MATEC Web of Conferences 42, 05004 (2016)

DOI: $10.1051 /$ matecconf/20164205004

(C) Owned by the authors, published by EDP Sciences, 2016

\title{
A Didactic Transmitter to Support the Communication and Learning Process of Children with Cerebral Palsy
}

\author{
Jonnathan Berrezueta-Guzmán ${ }^{a}$, Felipe Coronel-Maldonado, Luis Serpa-Andrade and Vladimir Robles-Bykbaev
}

GIIATa, Universidad Politécnica Salesiana, Calle Vieja12-30 y Elia Liut, Cuenca, Ecuador

\begin{abstract}
Nowadays, more than one billion people live with some form of disability (almost $15 \%$ of the world population). In this line, the preterm and low weight in neonates constitute important public health problems, especially in low and middle income countries. Infants who survive preterm birth are at increased risk of developing neurological problems such as Cerebral Palsy (CP) and impaired cognitive function. The CP comprises a series of disturbances in brain functions, motor, hearing, vision and learning for people who have it. In the same way, this disease does not allow to patients to use ICT tools to express their feelings, ideas, and needs, or in general, improve their learning process. On this basis, in this paper we present a ICT -based tool that relies on an embedded system and a mobile application, able to be used by patients that can perform slight head movements, or hand movements. Likewise, our system can detect these movements to help during the communication or learning tasks. The system was evaluated and adjusted in several tests carried out with 47 children ( 20 girls, and 27 boys). The achieved results are encouraging, and have shown $89 \%$ of acceptance by the patients.
\end{abstract}

\section{Introduction}

The CP is directly related to the central nervous system disorders, motor skills, listening and learning difficulties caused by lesions in the brain that mostly occurs while the baby grows in the wo mb or in the first years of life, when the baby is still developing. Likewise, it is important to mention that in some cases it is no possible to determine what causes $\mathrm{CP}$ [3].

Given that CP produces several problems related with motor abilities and the normal learn ing process, we have developed a system able to transmit messages (that express the patient's feelings, needs, or ideas) and support several activities related with special education. Our system can used with smartphones or tablets, and was designed to be used by patients of the Cerebral Palsy Institute of Azuay (Instituto de Parálisis Cerebral del Azuay). This institution is an Ecuadorian non-profit organization that attends children with different kinds of disabilities in Cuenca, Ecuador. In the same way, our system as the aim of providing a new alternative to carry out the therapy activities through the use of multimedia resources, remote communication, and patient monitoring. The rest of the paper is organized as follows. Some important facts related with CP and his treatment/therapy is presented in Section 2. Section 3 describes our system as well as the hardware and software elements. The pilot experiment that we have carried out and the preliminary results are depicted in Section 4. Finally, the Section 5 contains some conclusions and ideas for future work.

\section{Cerebral palsy: a brief overview}

The CP is a disease that can be produced due lesions suffered by child during the pregnancy or his/her first months of life. In some particular cases, these lesions are due to low oxygen levels in the brain (hypoxia) [3]. Other important causes of this disease are the premature birth and the following conditions: intracranial hemorrhage (bleeding in the brain), traumatic brain injuries, severe jaundice, brain infections (bacterial meningitis or viral encephalitis), and infections suffered by the mother during the pregnancy (even infections that are not easily detected) [4].

The signs and symptoms of $\mathrm{CP}$ are different according to each case and are included in a wide range (from mild to severe) that can affect one side of the body or both, and even legs or arms or both at the same time respectively [3, 4]. Likewise, in some cases, these symptoms can be detected during the first months of life, when the doctors or specialists can see some of the following clues: delays in the children's ability to achieve something, difficulties to sit, turn, crawl, walk, etc. [4, 5]. The spastic cerebral palsy is one of the most common types of CP. This disease is characterized by the loss of movement in different muscle groups due to stiff joints and the development of muscle tension with the passage of time. In the same way, as the patient grows, he/her can suffer from a combination of paralys is with a muscular contracture, several abnormal movements during the walk and loss of coordination $[5,6]$.

${ }^{\mathrm{a}}$ Corresponding author: jberrezuetag@est.ups.edu.ec 


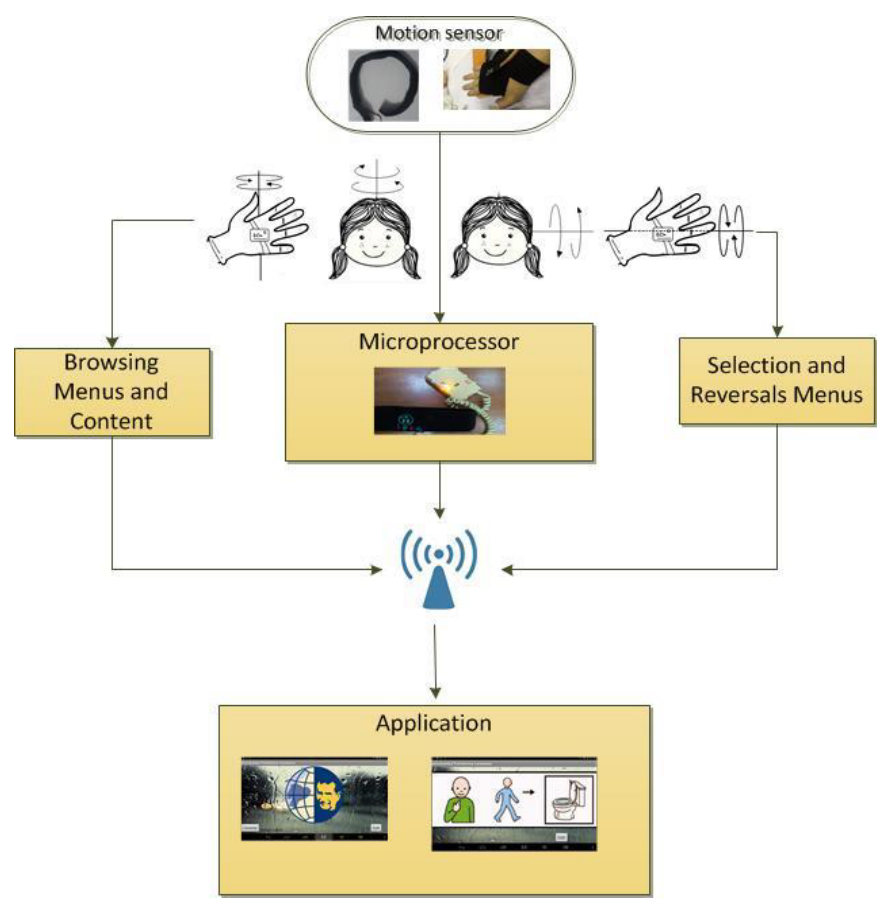

Figure 1. The proposed system: overview of elements.

This disease is related with other disorders as the following: dysarthria, hearing and visual impairments, learning difficulties, intellectual disabilities, etc. However, in some cases the intelligence is not totally affected [6].

Due to the symptoms related with CP, the patients can suffer from complications of motor skills such tremors, flaccidity, incoordination, thin bones (with risk of suffering hip dislocation or sclerosis), etc. In the other hand, the physiologic complications can include malnutrition, intestinal occlusion, and even pneumonia due to suffocation. The central nervous can be affected too by several problems, e.g., approximately half of the patients suffer from convulsions and recurrent seizures, and in several cases they present decrease of the intellectual and communication capacity $[6,7]$.

\subsection{Treatment/therapy for CP}

The main goal of the therapy/treatment for a patient suffering from CP is to develop as many skills as is possible for reaching an independent life (in the as far as possible). Therefore, it is important for team of experts (therapists, doctors, psychologists, and relatives and caregivers) conduct in a proper way the different stages related with this therapy process (diagnostic, assessment, and intervention) based on the symptoms present, and trying to prevent future complications (given that this disability not necessary affect the life expectancy of the patient) [7]. In the medical side, it is necessary to have the support of specialists in rehabilitation, pulmonology and gastroenterology with the aim of providing adequate diagnosis and monitoring services as magnetic resonances, audiometry tests, visual and hearing exams, etc. The results of these exams are important to determine the patient general condition, and they allow doctors prescribing drugs to control the recurrent seizures, relax the muscles, or conducting surgeries of different kinds (e.g. some patients require tubes feeding or the cutting of certain nerves of the spinal cord to reduce the pain and spasticity) $[8,9,10]$.On the other hand, it is fundamental for patients with $\mathrm{CP}$ to receive complementary treatment activities at home that can with her/his healthcare. For example, some patients require good nutrition and intestinal protection with softening of feces, fluids, fiber and laxatives in addition protection against injuries to their joints $[9,10]$. The prenatal care reduces significantly the risk of suffering $\mathrm{CP}$ in children. In the most of cases, when a wo man presents complications during pregnancy and is treated in time at a prenatal clinic, is possible to prevent lesions that cause disorders in the brain of the fetus $[11,12]$.

\section{The proposed system}

We have developed an embedded system that allows users to perform remote communication taking advantage of any available mobile device (s martphone or tablet) based on the Android Operative System (OS). W ith this aim, the system has a mobile application that provides services to establish the communication with the patient, and contains different educational materials and activities. Given that our system is portable, it is possible to use it at home or in any place where the patient goes..

Some of the most important features of the developed systemare described below (Figure 1):

- The system relies on two main modules: an electronic device that detects and registers the head/hand movements made by patient, and a mobile application that supports the communication and learning processes.

- To register the movements made by patient, the system uses two different adjustable elements: a headband and a hand belt. 
- The entire system (both the electronic device as the application) was developed using open source tools and elements (Arduino and Java.).

- The system can easily incorporate new modules to perform new communication or learning activities.

- Each therapist can include his/her multimedia materials for the different exercises and activities that are included in the mobile application.

As was mentioned above, the electronic device was designed for two types of patients, according to his degree of disability: the first one is intended for children who have a high degree of disability and its motor activity is limited solely to the head movement, while the second option is for those which are able to use their hands. In this line, the device has two types of sensors:

a) An adjustable headband made with velc ro that has a soft texture, and contains inside a accelerometer of $9 \mathrm{~mm}$ with 3 degrees of freedom (model: MMA7361L). This element provides a set of 3D coordinates of the position of the head in the space.

b) A bracelet that fits to the back of the palm of the hand that is made with the same materials and works with same principle of the headband.

In both cases the data processing it is carried out using an Arduino Nano device that encodes and sends the results of the position head or hand position to the mobile device through Bluetooth (using a JY-MCU HC-06 module). The electronic uses a lithium battery that provides a voltage of $3.8 \mathrm{~V}$ to $0.5 \mathrm{~A}$ as source of energy. This battery is rechargeable using USB port, and given the low consumption of the device is possible to use it during one week (with 3 years of lifetime). The case of the device is made in acrylic with a cuff with velcro adjustable wheelchair as well as to the arm of the patient (depending on his/her condition and particular needs).The mobile device makes possible that patients can use the transmitter at the institute or school, at home or in any place where is required. In the same way, this device help to entertain children and does not generate discomfort when using it, given that is easily adjustable to any head or hand sizes.

The Android application provides a graphical user interface that it is easy to understand, given that the options menu consists on pictograms that represent the patient's needs and teaching options. Both functions have multimed ia content of high quality, which responds to the movement of the head or hand that is controlled by the headband or bracelet, respectively. The most important options provided by the mobile application are the following:

- Expressing needs: the system contains several options to express the patient's needs as: hungry, toilet, sleep, born, among others. These needs are displayed using graphics (pictograms) and sounds.
- Educational contents to learn the following concepts: animals (domestic and wild), parts of the body, family, colors, shapes, among others.

\subsection{Operation parameters}

The operating parameters consist on the different functionalities that patient is able to run through the different menus of the mobile application (without making contact with the mobile device). To achieve this, the patient only needs to make slight movements with his/her head or hand. The process of interaction with the application is the following:

- In the main menu the patient can selected between two options: the transmitter of needs, or educational content. To select one of these options, the patients must to move the head/hand to right or left. For the therapists are provided the two options: a connection button (to start connection between the mobile device and the electronic device) and an exit button.

- The educational content menu shows the different categories mentioned above, and the patient can select the desired category using a vertical movement (from up to down). Once the exercises are finished, the patient can back to the previous menu using another vertical movement (from down to up).

In summary, only in the main menu the user must make left or right head/hand movements, while in the rest of the application are used vertical movements. In the same way, it is important to mention that these movements can configured according to each patient characteristic as sizes of his/her body, head or hand speeds, or slower movements due other difficulties.

\section{Preliminary results}

The Cerebral Palsy Institute of Azuay (IPCA) is a nonprofit organization that has been providing attention to children with disabilities since 33 years ago. Currently, the IPCA provides diagnosis and intervention services for people suffering from cerebral palsy in Cuenca city (province of Azuay). Nowadays, this institution helps more than 93 patients among boys, girls and adolescents who daily come to the institution to receive free therapy. The attention services are provided by 10 teachers, 6 therapists, and 8 professionals of the admin istrative staff (a team of 24 people in charge of the center).

In order to analyze the real feasibility of the proposed system, we have worked with children with CP that suffer severe motor functions, and are in the 7-12 age range. The evaluation of the system was done in this way: once the therapist has put bands on patients, he/she makes several questions and orders that must be answered/accomplished by each patient using the system.

The system was tested in short sessions of 4 minutes (due to the effort that must be done by each patient to achieve the goals). Likewise, the initial tests allowed us to calibrate the sensors and correct some bugs of the system (first week). In the second testing phase (second 
week) the patients have shown high levels of acceptance to use the device $(80 \%)$, and the activities were performed in a better way.

Table 1 shows the different age ranges of the patients with $\mathrm{CP}$ that have participated in the evaluation of the system.

Table 1. Patients with CP participating on the experiment.

\begin{tabular}{|c|c|c|}
\hline Age (years) & Boys & Girls \\
\hline $\mathbf{7}$ & 3 & 2 \\
\hline $\mathbf{8}$ & 6 & 6 \\
\hline $\mathbf{9}$ & 7 & 3 \\
\hline $\mathbf{1 0}$ & 6 & 4 \\
\hline $\mathbf{1 1}$ & 3 & 4 \\
\hline $\mathbf{1 2}$ & 2 & 1 \\
\hline
\end{tabular}

The Figure 2 shows the results achieved after the evaluation (in terms of device functionality and acceptance by patients). As we can see, $89 \%$ of patients has felt comfortable using the device, and has reached the goals established in each therapy activity. However, after conducting pilot experiment we have noticed that it is fundamental personalizing the device according to user profile. In the same way, these results shown that development of the system must to continue, as well as the improvements.

\section{Results feasibility device}

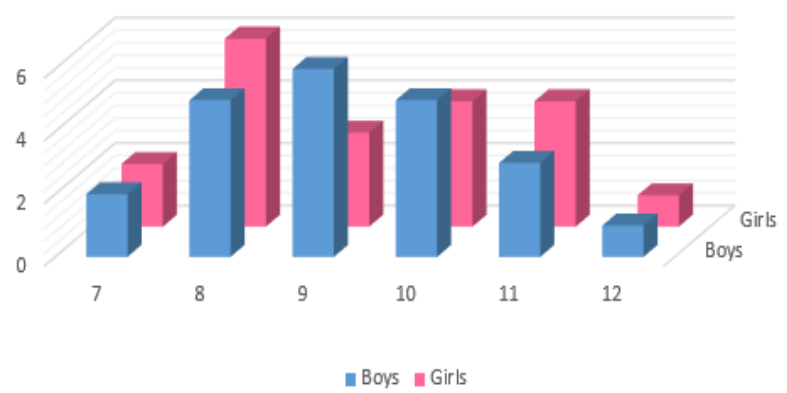

Figure 2. Preliminary results of the pilot experiment (in acceptance terms).

\section{Conclusions}

In this paper we have presented a new system to provide support for communication of children suffering from $\mathrm{CP}$. In the same way, our proposal can be used to support the learning process of this kind of patients.

It is important to bear in mind that each patient has particular needs, requirements, and a specific profile (medical and educational). The system allows therapis ts to reduce the time required during therapies, and provides support to stimulate the patient's motor skills. As lines of future work we propose the following ones:
- To develop a notification module able to send SMS for patient's relatives.

- To design an intelligent module to automatically select the exercises and activities given the patient's profile.

\section{Acknowledgements}

We would like to thank Dr. Hernán Tenorio and all the collaborating people from Instituto de Parálisis Cerebral del Azuay (IPCA).

\section{References}

1. OMS, Informe mundial sobre discapacidad, online $<$ http://www.who.int/disabilities/world_report/2011/e $\mathrm{s} />$

2. OMS, Biblioteca de salud reproduciva, OMS, Biblioteca de salud reproduciva, online $<$ http://apps.who.int/rhl/pregnancy_childbirth/compli cations/preterm_birth/cd004661_lumbiganonp_com/ es $/>$

3. Illescas Vásquez, Margarita Raquel, Desarrollo de un software educativo para el Instituto Fiscal Especial "Stephen Hawking" en el área de Lenguaje y Comunicación para niños con parálisis cerebral nivel 1; directora Paola Cristina Ingavélez Guerra. Cuenca [Ecuador], 2010.

4. Ángel Latorre Latorre, Trastornos motores: adaptación curricular y casos prácticos; Valencia : Tirand lo blanch, 2010.

5. Pineda Guncay, Claudio Is mael, "Módulo de comunicación para niñas y niños que presentan parálisis cerebral con pérdida del habla"; director Fredy Marcelo Rivera Calle. Cuenca [Ecuador], 2012.

6. Astudillo Astudillo, Christian Geovanny, "Diseño y construcción de un sistema de interacción con el computador para niños con parálisis cerebral"; director Luis Guillermo Abad Calvo. Cuenca [Ecuador], 2012.

7. Andrade Barriga, Paul Andrés. Re-ingeniería de un transmisor inalámbrico portable de necesidades básicas para niños con parálisis cerebral; director Eduardo Guillermo Pinos Vélez. Cuenca [Ecuador], 2015.

8. Guía Rápida de consulta para padres y profesionales, "Trastornos de la motricidad" $<$ http://www.health.ny.gov/publications/5308.pdf $>$

9. Johnston MV. Encephalopathies. En: Klieg man RM, Behrman RE, Jens on HB, Stanton BF, eds. Nels on de libros de texto de Pediatría. 18th ed. Philadelphia, Pa: Saunders Elsevier; 2007: chap 598.

10. Sakzewski L, Ziviani J, Boyd R. Systematic review $\mathrm{y}$ meta-analysis of therapeutic management of upper-limb dysfunction in children with congenital hemiplegia. Pediatría. 2009;123:e 1111-1122.

11. Albright, A.L., Cervi, A. y Singlatary, J. Intrathecal baclofen for spasticity in cerebral palsy (Baclofeno intratecal para la espasticidad en la parálisis cerebral). JAMA 1991; 265: 14181422. 
12. Capón Albarracín, Marco Geovanny. "Diseño e implementación de una aplicación móvil de soporte para el desarrollo articulatorio en niños con parálisis cerebral y problemas asociados" Cuenca [Ecuador], 2014. 